\title{
ALIMENTAÇÃO ÀS FAMÍLIAS EM VULNERABILIDADE SOCIOECONÔMICA DA COMUNIDADE DE GUADALAJARA- PAUDALHO/PE, DURANTE A PANDEMIA DO NOVO CORONAVÍRUS NO ANO DE 2020
}

\section{ARTIGO ORIGINAL}

SOARES, Vinícius Paz do Nascimento¹, SOARES, Anísio Francisco²

SOARES, Vinícius Paz do Nascimento. SOARES, Anísio Francisco. Alimentação às famílias em vulnerabilidade socioeconômica da comunidade de GuadalajaraPaudalho/PE, durante a pandemia do novo Coronavírus no ano de 2020. Revista Científica Multidisciplinar Núcleo do Conhecimento. Ano. 06, Ed. 10, Vol. 05, pp. 25-33. Outubro 2021. ISSN: 2448-0959, Link de acesso: https://www.nucleodoconhecimento.com.br/saude/vulnerabilidade-socioeconomica, DOI: 10.32749/nucleodoconhecimento.com.br/saude/vulnerabilidadesocioeconomica

\section{RESUMO}

Uma alimentação saudável, uma boa prática alimentar ou ainda, a ingestão de alimentos adequados em quantidade e qualidade suficientes para suprir as necessidades nutricionais, são essenciais para todos os cidadãos. O alimento deve permitir o crescimento e o desenvolvimento adequado do ser humano, sem exceder a capacidade funcional orgânica de seu sistema cardiovascular, digestório e renal. Tal prática possibilita a prevenção de várias doenças na infância e na vida adulta futura, entre as quais as deficiências nutricionais, as doenças crônicas, o sobrepeso e a obesidade. Diante desses fatores, em função das consequências do fechamento das escolas e encerramento de diversas ações solidárias governamentais

\footnotetext{
${ }^{1}$ Discente do Curso de Zootecnia. ORCID: https://orcid.org/0000-0002-5637-1543

2 PhD em Bioquímica e Fisiologia, Mestre em Fisiologia, Biólogo. ORCID: https://orcid.org/0000-0003-14937964
}

RC: 99052

Disponível em: https://www.nucleodoconhecimento.com.br/saude/vulnerabilidadesocioeconomica 
provocadas pela pandemia da COVID-19, houve um aumento da fome e a desnutrição em inúmeros lares brasileiros. Sendo as comunidades localizadas nas periferias dos grandes centros as mais afetadas, tendo em vista, serem considerados os bairros/cidades dormitórios, onde habitam um alto percentual de trabalhadores que perderam seus empregos. Este trabalho objetivou relatar a ação realizada de agosto a dezembro de 2020 na comunidade de Guadalajara, Paudalho/PE, através do qual foi realizada distribuição de sopas em locais estratégicos. Após identificação e local para a realização do projeto, foi realizado um pré-cadastro, através do qual se identificava quantos membros da família habitavam na mesma residência, sendo esta informação crucial para que fosse definido o quantitativo de sopa a ser distribuída a cada semana. Ao longo do projeto foi possível atender, semanalmente, em média 100 beneficiados, majoritariamente mulheres, que se dirigiam ao local de distribuição para receber a refeição, O estudo revela a necessidade urgente de maior investimento em políticas públicas que possam reduzir a fome e a má nutrição no país, bem como minimizar a pobreza extrema.

Palavras-chave: Alimentação saudável, desenvolvimento infantil, ações solidárias.

\section{INTRODUÇÃO}

Um problema de saúde pública que vem por muitos anos afetando, principalmente, países em desenvolvimento, incluindo o Brasil, é a desnutrição. Esse mal se faz presente em vítimas de diversas faixas etárias, porém é especialmente danoso às crianças, que podem desenvolver diversos problemas como más formações fisiológicas e mentais que, muitas vezes, perduram ao longo da vida (MÉDICOS SEM FRONTEIRAS, 2018).

Embora a desnutrição, quase sempre, esteja associada à magreza, estudos demonstram que a situação é refletida pela falta de vitaminas, minerais e outros elementos essenciais para o pleno funcionamento do organismo. Assim sendo, é possível que crianças que estejam acima do peso para sua idade, sejam também 
consideradas desnutridas, pois a dieta pode ser rica em açúcar e gorduras e pobre nos alimentos que fornecem os nutrientes fundamentais para o organismo o que é considerada uma má nutrição (RIBEIRO, 2020).

O processo de desenvolvimento e crescimento é bastante complexo, envolvendo não apenas aspectos genéticos, nutricionais, endócrinos, mas também os psicossociais. No entanto, via de regra, é possível reconhecer e projetar uma curva de crescimento linear e de ganho ponderal de peso da infância à adolescência. Monitorar o desenvolvimento e a saúde da criança e do adolescente através de avaliação do padrão nutricional é um dispositivo essencial para a prevenção e/ou diagnóstico precoce de possíveis distúrbios nutricionais, a exemplo da desnutrição. Neste sentido, acompanhar a curva e o ritmo de crescimento possibilitam a detecção precoce dos distúrbios nutricionais e os riscos por ele acarretados (ALBUQUERQUE, 2015).

No final de fevereiro de 2020 foi registrado no Brasil a primeira contaminação pelo novo coronavírus (COVID-19) que é uma doença infecciosa causada pelo vírus SARS-CoV-2. Na ocasião, o governo federal, adotou algumas medidas sanitárias de enfrentamento a COVID-19, que foram complementadas pelos governos estaduais. Em Pernambuco, a regulamentação dessas medidas ocorreu através do decreto $\mathrm{n}^{\circ}$ 48.810 de 16 de março de 2020, em seu Art. 6-A. Nesta mesma linha, foram apresentadas regras claras de isolamento e distanciamento social, tendo em vista a gravidade e ascensão da pandemia.

A realidade pandêmica causada pelo SARS-CoV-2 aumentou ainda mais as consequências da fome e desnutrição. Sabe-se que uma alimentação saudável depende, inevitavelmente da renda familiar; por isso, a realidade da pobreza e da desigualdade social, que há longos anos pereniza no Brasil, tem sido apontada como uma das causas mais relevantes na gênese da desnutrição, levando a mesma a ser entendida essencialmente como uma questão de saúde pública (FRAGA e VARELA, 2012). Neste sentido, se faz extremamente necessárias a adoção de ações solidárias e políticas públicas sociais que possam prestar apoio às 
comunidades mais carentes, para que estas não vivenciem a má nutrição/desnutrição. Tendo em vista o exposto, o trabalho teve como objetivo relatar a ação realizada de agosto a dezembro de 2020 na comunidade de Guadalajara, Paudalho/PE, através do qual foi realizada distribuição de sopas em locais estratégicos, oportunizando às famílias uma refeição nutricionalmente completa, ao menos uma vez ao dia, visando a recuperação da autoestima e o desenvolvimento fisiológico dentro dos parâmetros normais, mesmo diante da pandemia do novo coronavírus.

\section{MATERIAL E MÉTODOS}

O projeto foi desenvolvido no município pernambucano chamado Paudalho. Ele está localizado na zona da mata norte do estado, possui 56.506 habitantes, uma densidade demográfica de 203,6 habitantes por km², situado a 86 metros de altitude, tendo as seguintes coordenadas geográficas: Latitude: $7^{\circ} 53^{\prime} 31^{\prime \prime}$ Sul, Longitude: $35^{\circ}$ 10' 37" Oeste, distante $44,1 \mathrm{~km}$ do Recife, capital do estado. O município de Paudalho apresenta um Índice de Desenvolvimento Humano (IDH) de 0,639 (IBGE, 2010). A comunidade escolhida foi a de Guadalajara que possui aproximadamente 15000 habitantes, está localizada ao longo da BR 408 distante $9 \mathrm{~km}$ do centro do município.

Segundo a Secretaria Municipal de Assistência Social do município (2020), responsável por gerir a política municipal de segurança alimentar e nutricional, através das ações emergenciais e estruturantes de combate à fome e extrema pobreza, o município possui um elevado percentual de famílias atendidas por programas sociais, apresentando, inclusive, muitas famílias nas quais as refeições fornecidas pelas escolas aos seus filhos chegam a ser a refeição mais completa do dia (SMDA, 2020).

O projeto foi desenvolvido no período de agosto a dezembro de 2020 , em parceria com alunos da Universidade Federal Rural de Pernambuco e voluntários que já 
mantém uma ação solidária de doação de alimentos a famílias da comunidade. Algumas etapas foram necessárias para a execução do projeto:

Levantamento da demanda: a equipe visitou semanalmente o local onde já ocorria a distribuição de alimentos a essas famílias e buscaram informações sobre endereço e quantidade de domiciliados, buscando identificar as famílias em situação de risco e vulnerabilidade socioeconômica, para então ser estimada a necessidade de investimento para a realização da ação. A coleta destas informações proporcionou a criação de um cadastro de beneficiados.

Levantamento da oferta: a equipe também buscou identificar quem eram e quantas eram as pessoas que faziam as doações, para que a ação fosse mantida após o encerramento da parceria com os universitários. A partir dessas informações, mais pessoas foram sensibilizadas a realizarem doações de insumos, sendo complementado com verba de custeio obtida para este fim, tendo em vista a meta de que esta ação se estendesse até dezembro de 2020.

Elaboração de folders: Posteriormente foi elaborado um folder com orientação sobre hábitos higiênicos saudáveis, importância do isolamento e distanciamento social para ser entregue durante a distribuição da refeição.

Local de cocção e distribuição: O local para recebimento de doações, preparo, cocção e distribuição da sopa foi nas dependências da igreja católica Nossa Senhora Auxiliadora, na própria comunidade. No preparo, as voluntárias utilizavam legumes, verduras, carnes com ossos e temperos diversos.

Distribuição da sopa: A equipe propôs um cronograma de distribuição da refeição, de modo que semanalmente, às sextas feiras, era servida a sopa acompanhada de pães. O cadastro prévio foi útil para que o preparo fosse estimado para servir cerca de 100 pessoas, evitando qualquer desperdício. 


\section{RESULTADOS E DISCUSSÃO}

A pandemia no novo coronavírus só acentuou ainda mais uma realidade vivenciada no Brasil, onde quase metade dos lares brasileiros são sustentados por mulheres. Com o desemprego, a situação de fome e pobreza extrema ficou ainda mais acentuada (BARBOSA, 2020). Esta situação ficou clara no momento das visitas em busca de realizar o cadastro para identificar as famílias a serem beneficiadas.

Ao longo do projeto, foram cadastradas e beneficiadas 100 famílias, que são compostas, majoritariamente, por mulheres como únicas ou principal provedoras do lar. Semanalmente, os beneficiados se dirigiam ao local de distribuição para receber a sopa. Como foi realizado o pré-cadastro sabia-se quantos membros da família habitavam na mesma residência e, a partir desta informação, era acrescida proporcionalmente mais porções de sopa ao beneficiário. Na Figura 01 pode ser observada a sopa distribuída aos beneficiários. 
Figura 1 - Sopa e pães distribuídos semanalmente entre os beneficiários cadastrados no projeto "sopão solidário" comunidade de Guadalajara, Paudalho/PE.

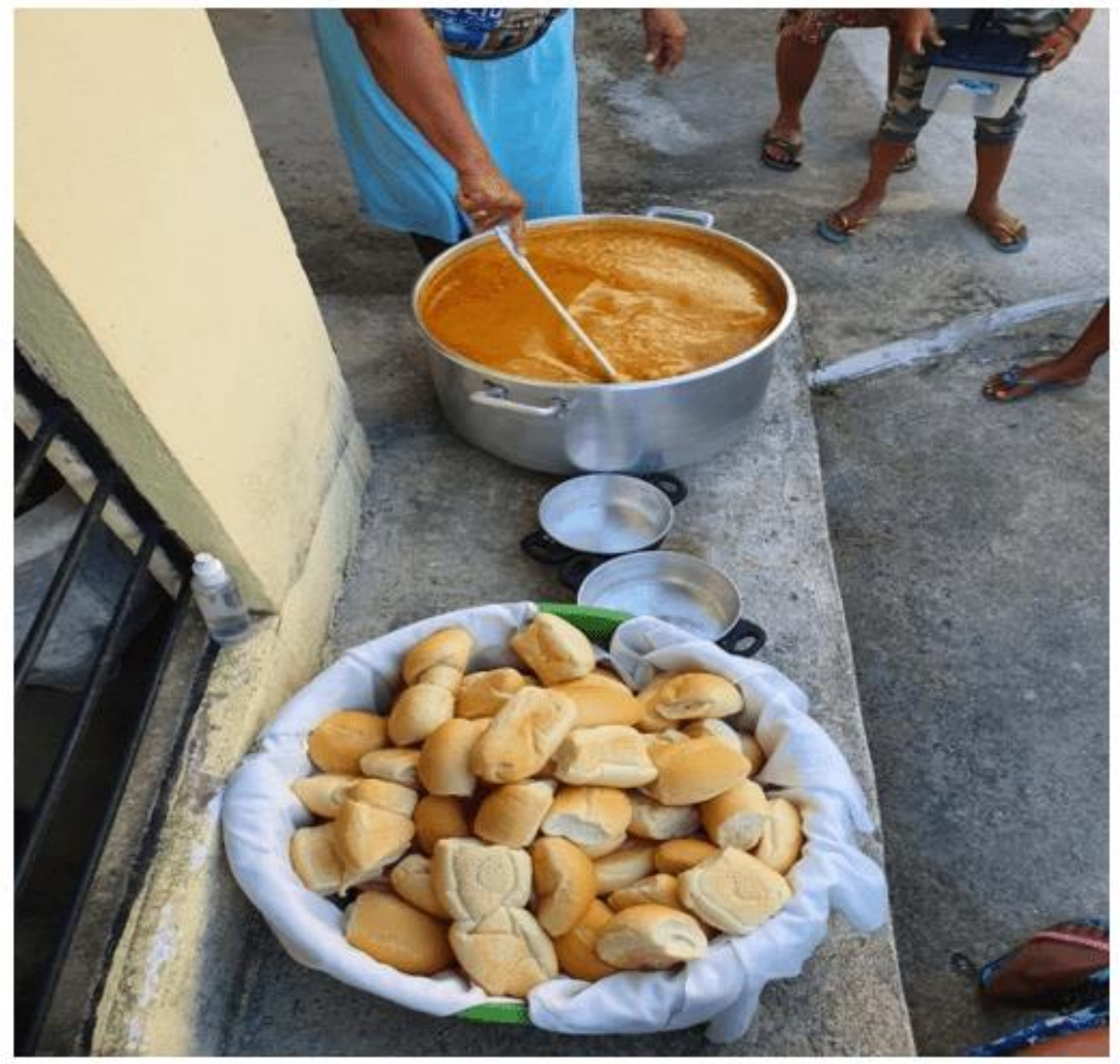

(Fonte da Imagem: próprio autor).

No início no projeto, foram identificados pouco mais de 20 voluntários doadores, que variavam no tipo de doação/contribuição mensalmente. A partir da implementação da ação, divulgação e transparência na condução desta, este número aumentou, chegando a 40 voluntários doadores, 3 meses após o início do projeto (Figura 2). Isto se deu, certamente, devido ao trabalho de sensibilização desenvolvido pela equipe, como também pelo aumento no volume do "sopão solidário" distribuído semanalmente. 
Figura 2 - Evolução do quantitativo de voluntários/doadores de insumos para o projeto "sopão solidário" ao longo de sua implantação.

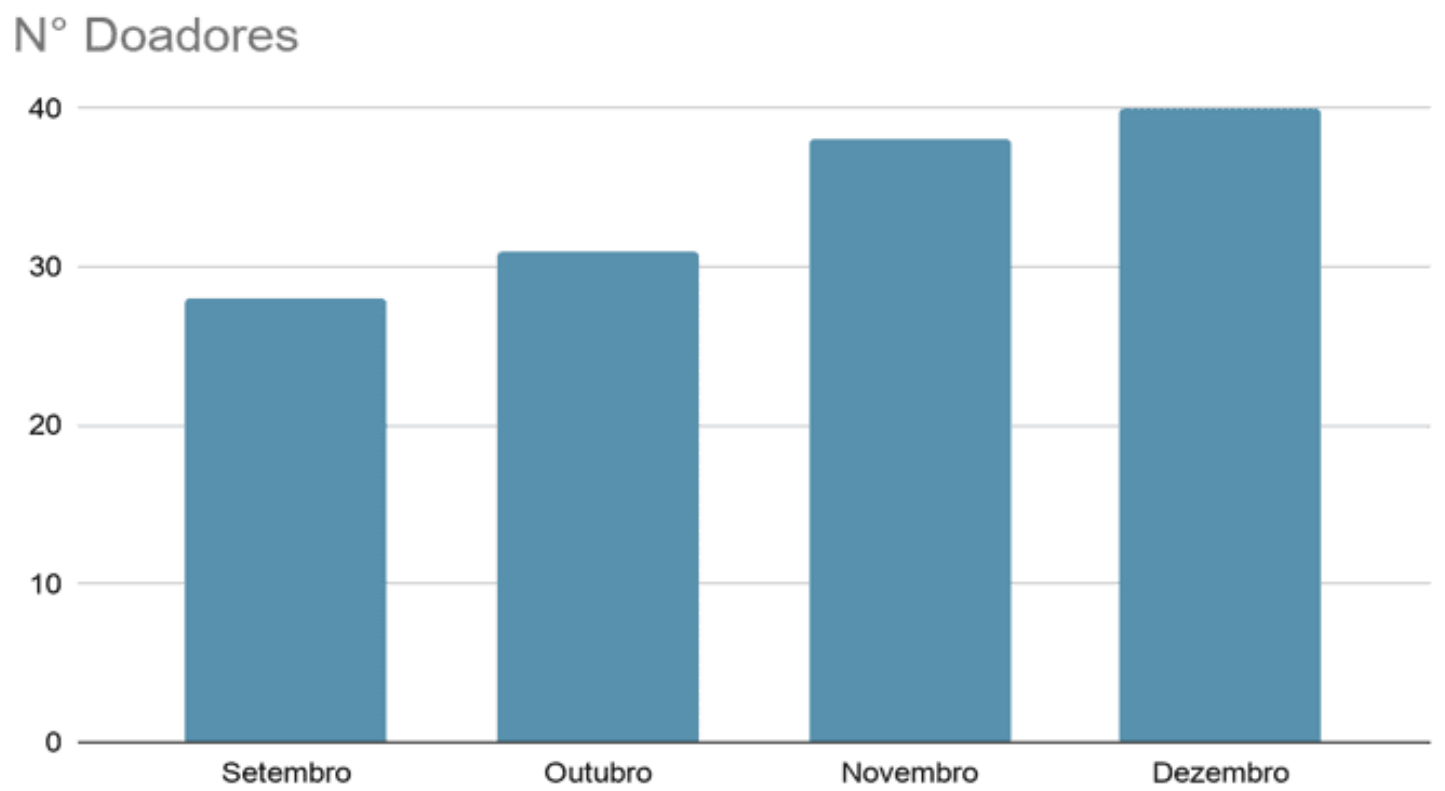

(Fonte da Imagem: próprio autor).

A política pública brasileira, na última década, expressa o enorme impacto que investimentos que visaram à redistribuição de renda e possibilitaram o acesso universal à educação, a saúde e melhorias no saneamento, podem refletir diretamente na desnutrição humana. Essas políticas precisariam estar no topo da agenda de priorização de qualquer gestor comprometido com o bem-estar e a melhoria da qualidade de vida dos cidadãos e das futuras gerações (MONTEIRO, 2009).

O projeto buscou sensibilizar um maior número de voluntários para obter mais doações/contribuições para, consequentemente, atingir mais beneficiados. A estratégia de sensibilização, proporcionou um aumento no número de voluntários, o que possibilitou a aquisição de maior quantidade de suprimento, a manutenção do projeto e o atendimento de mais famílias. 


\section{CONSIDERAÇÕES FINAIS}

Apesar de ter sido beneficiado um número limitado de famílias, o projeto possui grande potencial para atingir uma parcela maior de necessitados ao longo do tempo, caso se estenda a ação voluntária por mais tempo, tendo em vista a situação atual da COVID-19. O público-alvo reflete a realidade de uma comunidade pobre e com alto índice de má nutrição, sendo ainda necessário maior sensibilização e auxílio por parte da população com ações voluntárias e/ou do governo com projetos sociais como este.

\section{REFERÊNCIAS}

ALBUQUERQUE, M. P. Como reconhecer os sinais de uma criança desnutrida. Cren, 2015. Disponível em: <https://www.cren.org.br/blog/2017/04/27/criancadesnutrida/>. Acesso em: 28, dez 2020.

BARBOSA, M. Força das mulheres: Correio Brasiliense, Atualizado em 16/02/2020. https://www.em.com.br/app/noticia/economia/2020/02/16/economia,1122167/. Acesso em: 30, ago 2021.

FRAGA, J. A. A.; VARELA, D. S. S. A relação entre a desnutrição e o desenvolvimento infantil. Revista da Associação Brasileira de Nutrição, v. 4, n. 5, p. 59-62, jan-jun 2012.

INSTITUTO BRASILEIRO DE GEOGRAFIA E ESTATÍSTICA. https://www.ibge.gov.br/cidades-e-estados/pe/paudalho.html>. Acessado em: 30 ago, 2021.

MÉDICOS SEM FRONTEIRAS. Desnutrição. Disponível em: <https://www.Rev. Assoc. Bras. Nutmsf.org.br/o-que-fazemos/atividades-medicas/desnutricao? >. Acessado em: 30 nov. 2020. 
MONTEIRO, C. A. A queda da desnutrição infantil no Brasil. Cad. Saúde Pública, Rio de Janeiro, 25(5):950-951, mai, 2009.

RIBEIRO, S. S. Desnutrição infantil: o que é, sintomas, e tratamento. Tua saúde, 2021. Disponível em: <https://www.tuasaude.com/desnutricaoinfantil/\#: :text=A\%20desnutrição\%20é\%20na\%20maioria,a\%20alimentação\%20pod e\%20ser\%20rica>.Acesso em: 09, jan 2021.

$\begin{array}{llll}\text { SECRETARIA MUNICIPAL } & \text { DE }\end{array}$ https://www.paudalho.pe.gov.br/portal/secretarias/secretaria-municipal-dedesenvolvimento-e-assistencia-social/. Acesso em: 28, ago 2021.

Enviado: Maio, 2021.

Aprovado: Outubro, 2021. 